\title{
Prevalence of pregnancy-relevant infections in a rural setting of Ghana
}

\author{
Fabian Völker ${ }^{1}$, Paul Cooper ${ }^{2}$, Oliver Bader ${ }^{1}$, Angela Uy ${ }^{1}$, Ortrud Zimmermann ${ }^{1}$, Raimond Lugert $^{1}$ \\ and Uwe Groß ${ }^{1,3^{*}}$ (D)
}

\begin{abstract}
Background: Although infectious diseases still account for a high burden of morbidity and mortality in sub-Saharan Africa, simultaneous investigations on multiple infections affecting maternal and child health are missing.

Methods: We conducted a cross-sectional, single-centre pilot study in a rural area of Ghana to assess the infectiological profile during pregnancy. Screening of 180 expectant mothers was done by vaginal swabs and serology to detect the most common pregnancy-relevant infections. They were also interviewed for potential risk factors, outcome of previous pregnancies, and socio-economic aspects.

Results: We found a high prevalence of infections caused by hepatitis B virus (16.7\% HBs antigen positive). In contrast, infections caused by hepatitis C virus (1.1\% anti-HCV) and HIV (0.6\%) were rare. Maternal malaria was frequent (10.6\%), despite increasing acceptance of intermittent preventive treatment during pregnancy (IPTp). Group B streptococci were present in $10.6 \%$ of all pregnant women. Absence of antibodies against varicella zoster virus in 43.2\%, Toxoplasma gondii in 26.8\%, parvovirus B19 in 20.0\%, and rubella virus in 15.7\% makes a significant proportion of pregnant women susceptible for acquiring primary infections. Whereas all study participants had specific lgG antibodies against human cytomegalovirus, infections with Listeria, Brucella, or Neisseria gonorrhoeae as well as active syphilis were absent.

Conclusions: Our pilot study in a rural community in Ghana indicates an urgent need for action in dealing at least with high-prevalent pregnancy-relevant infections, such as hepatitis B, malaria and those caused by group B streptococci. In addition, the resulting prevalence rates of various other infections may offer guidance for health officials to prioritize possible future intervention schemes.
\end{abstract}

Keywords: Pregnancy, Infections, Hepatitis B, Group B streptococci, Malaria, Ghana

\section{Background}

Between 1990 and 2015 the maternal mortality ratio in sub-Saharan Africa decreased from 987 maternal deaths per 100,000 live births to 546 , but is still significantly higher than in high-income countries with only twelve deaths per 100,000 live births $[1,2]$. The main medical causes for maternal death are hemorrhage, hypertensive disorders and infections which are accompanied by high mortality rates in low-income countries [3]. Concurrently, maternal health is closely linked to child health through the potential prenatal or perinatal transmission of pathogens. Hence, pregnancy-relevant infections present a major

\footnotetext{
* Correspondence: ugross@gwdg.de

${ }^{1}$ Institute for Medical Microbiology, University Medical Center Göttingen, Kreuzbergring 57, D-37075 Göttingen, Germany

${ }^{3}$ Göttingen International Health Network, Göttingen, Germany

Full list of author information is available at the end of the article
}

reason for high child morbidity and mortality rates in subSaharan Africa. Indeed, 1.2 million newborns die annually in sub-Saharan Africa with pregnancy and childbirth complications including childhood infections being among the five biggest challenges [4]. Despite pregnancy-relevant infections being an intensive field of research, their causes and possible co-infections are rarely specified on the pathogenic level in these countries. Only Plasmodium and HIV (co-) infections are often in the focus of research [5].

Based on this limitation in knowledge, the aim of our pilot study was to determine the prevalence rates of pregnancy-relevant infections which might have an impact on newborn health. We also aimed to evaluate the influence of socio-economic factors, such as access to medical services, age, origin and education on the prevalence of certain infectious diseases. 


\section{Methods}

\section{Study design}

The study population consisted of pregnant women from the Jomoro, Nzema East Municipal, Ahanta West, and Ellembelle district (Western Region of Ghana) attending the hospital for delivery during time of investigation. The women had a gestational age of $\geq 39$ weeks or an expected delivery within $\leq 1$ week (independent of the week of pregnancy), hence including term and preterm deliveries. Nonhospitalized preterm birth could not be taken into account. A standardized questionnaire was used to collect general, demographic, and obstetric data (see Additional file 1). Specific antenatal medical care services were recorded. For data evaluation, we analyzed the participating women for accessibility of the hospital. Thus two sub-groups, one with relatively good access (origin: Ellembelle district, mean journey time $144 \mathrm{~min}$ ) and one with limited access (origin: surrounding districts, mean journey time $229 \mathrm{~min}$ ), were created.

Vaginal swabs were used to detect group B streptococci (GBS), Listeria monocytogenes, Neisseria gonorrhoeae, Chlamydia trachomatis as well as herpes simplex virus (HSV)1/-2. Blood/serum samples were analyzed for the presence of Plasmodium species (spp.) or antibodies against Toxoplasma gondii, Treponema pallidum, Brucella spp., rubella virus, varicella zoster virus (VZV), HSV1/-2, parvovirus B19 (PB19), human cytomegalovirus (HCMV), hepatitis B virus (HBV), hepatitis C virus (HCV), and HIV (combined detection of antigen and antibodies), respectively. Available $\mathrm{HBs}$ antigen (Ag)-positive serum samples were subsequently tested for $\mathrm{HBeAg}$ and elevated liver enzymes (alanine aminotransferase, ALT).

\section{Cultivation and identification of bacteria}

Vaginal swabs were inoculated on blood and chocolate agar. Preliminary identification of bacteria was done at the local laboratory and subsequently confirmed by matrix-assisted laser desorption/ionization time-offlight mass-spectrometry (MALDI-TOF MS) (MALDI Biotyper, Bruker Daltonics, Bremen, Germany) in Göttingen, Germany.

\section{Nucleic acid amplification}

Real-time PCR was performed with the LightCycler 1.5 (Roche, Mannheim, Germany) to detect C. trachomatis and HSV in vaginal swabs. The Artus HSV-1/-2 LC PCR Kit (Qiagen, Hilden, Germany) was used to amplify HSV-1/-2 DNA. An in-house real-time PCR was applied for the detection of $C$. trachomatis. In brief, a 554 bp DNA fragment of the 16S rRNA gene was amplified using primers C161 (cgt cta ggc gga ttg aga g) and C162 (atc cac atc aag tat gca tcg) together with the LightCycler FastStart DNA Master SYBR Green I-Kit (Roche). Initial denaturation for $10 \mathrm{~min}$ at $95{ }^{\circ} \mathrm{C}$ was followed by 40 cycles of denaturation $\left(10 \mathrm{~s}, 95{ }^{\circ} \mathrm{C}\right)$, annealing $\left(5 \mathrm{~s}, 60^{\circ} \mathrm{C}\right)$ and elongation $\left(20 \mathrm{~s}, 72^{\circ} \mathrm{C}\right)$.

\section{Malaria and serological tests}

Plasmodium parasites were detected by peripheral blood smear and light microscopy using the Field's stain technique. Serum samples were screened for pathogenspecific antibodies or antigens as listed in Table 1.

\section{Sample size estimation and statistical analysis}

The sample size was estimated based on Kish's formula [6]. A presumptive prevalence of $35 \%$ was estimated for most infections and used to maximize and get a reasonable number of samples to assess different infections in the target population. Characteristics of our study population were valued by using descriptive statistics. Chi square test was applied to compare categorical variables. A significance level of $P<0.05$ was considered statistically significant. In order to estimate the impact of different independent variables that determine an outcome (e.g. seropositivity of a cohort) we used a logistic regression model. Data analysis was performed by using Stata 12 statistical software (www.stata.com).

\section{Results}

\section{Study population and anamnesis}

A total of 180 pregnant women $(60 \%$ of the overall 300 deliveries during the study period) participated in the screening that took place in Eikwe/WR, Ghana during a three months period from October 2011 to January 2012. Emergency obstetric cases or deliveries during hospital night shift were excluded.

The mean age was 26.3 years (range $14-48$ years). The average participant had her third pregnancy and less than two children. With up to $32 \%$, the rate of illiteracy was high. The study population was divided into two subgroups according to the distance of living to the hospital which represented either good or limited access to medical care ( $N=9$ missing observations). Eighty-eight women were resident in the same district as the local hospital (subgroup 1) whereas 83 women had to travel from the surrounding districts (subgroup 2).

On average, an antenatal clinic (ANC) was visited 7.8 times during the current pregnancy. Based on the interview data, $83 \%$ received Fansidar as intermittent preventive treatment during pregnancy (IPTp), but only $34 \%$ were treated with three doses as recommended. Although guidelines in Ghana recommend screening for syphilis, hepatitis B and HIV during pregnancy, only $48 \%$ of the study population mentioned that they were screened for T. pallidum infection and only $17.2 \%$ were tested for HBsAg during their regular antenatal service. In contrast, $89 \%$ of pregnant woman had formerly received an HIV test. 
Table 1 List of applied serological assays

\begin{tabular}{|c|c|c|}
\hline Object of assay & Test system & Producer \\
\hline Toxo-lgM & VIDAS Toxo-IgM ELFA & bioMérieux, France \\
\hline Toxo-lgG & VIDAS Toxo-IgG ELFA & bioMérieux, France \\
\hline Toxo-lgG Avidity & VIDAS Toxo-IgG avidity ELFA & bioMérieux, France \\
\hline HBsAg (HBV) & HBsAg(v2)/AXSYM & Abbott, Germany \\
\hline HBsAg (HBV) & HBsAg ElA Test Kit & $\begin{array}{l}\text { Ascon, USA (for comparison; rapid test } \\
\text { with excellent performance used in Ghana) }\end{array}$ \\
\hline HBeAg (HBV) & HBeAg(v2)/AXSYM & Abbott, Germany \\
\hline Anti-HCV-lgG & HCV version 3.0 Anti-HCV & Abbott, Germany \\
\hline Anti-HCMV-lgM/lgG & Cytomegalovirus lgM/lgG & Serion ELISA classic, Germany \\
\hline Rubella IgM/lgG & Rubella virus (lgM/lgG) & Serion ELISA classic, Germany \\
\hline $\mathrm{HIV}$ Ag/Ab & HIV Ag/Ab Combo & Abbott, Germany \\
\hline Anti-PB19-lgM/lgG & Parvovirus B19 lgM/lgG & Mikrogen recomWell, Germany \\
\hline Anti-VZV-lgA/lgG & Varicella-zoster virus (IgA/lgG) & Serion ELISA classic, Germany \\
\hline Anti-HSV-lgM/lgG & Herpes simplex virus $1+2 \operatorname{lgM} / \operatorname{lgG}$ & Serion ELISA classic, Germany \\
\hline Treponema-lg & Serodia TPPA & Fujirebio, Japan \\
\hline T. pallidum-lg & FTA-ABS & Sekisui Diagnostics, Japan \\
\hline Cardiolipin-lg & VDRL & Omega Diagnostics, Germany \\
\hline
\end{tabular}

\section{Prevalence of pregnancy-relevant infections}

The results of direct pathogen detection or serologic determination of pathogen-specific antibodies are summarized in Table 2. According to the findings, the various pregnancy-relevant infections were classified into four statuses; (i) current infection, (ii) high proportion of women being susceptible for acquiring primary infection, (iii) past infection, and (iv) absence of infection.

\section{Prevalence of current infections}

Serum samples from 174 women $(N=6$ missing observations) were screened for HBsAg detecting a prevalence of $16.7 \%(N=29)$. Five out of 23 available HBsAgpositive serum samples $(21.7 \%)$ also tested positive for HBeAg. All of them had ALT values below cut-off levels indicating the absence of liver damage. Neither of the $\mathrm{HBsAg-positive} \mathrm{pregnant} \mathrm{women} \mathrm{received} \mathrm{antiviral} \mathrm{treat-}$ ment, nor were they vaccinated against HBV. The prevalence of hepatitis B was considerably higher in subgroup 1 (21.8\%) compared to subgroup $2(11.2 \% ; p<0.05)$. However, none of the socio-economic factors were associated with HBsAg prevalence (data not shown). All HBsAg-positive mothers were HIV negative.

Only $1.1 \%(N=2)$ of the entire study population had HCV-specific antibodies. Likewise, only 1 out of 173 ( $N=7$ missing observations) blood samples was tested positive for HIV-specific antibodies/antigens.

Screening of 180 blood samples detected Plasmodium parasites in $10.6 \%(N=19)$ of the samples with eleven infected women harboring a low level, three a mid-level, and five a high level parasitemia.

Among the 180 study participants, a vaginal GBS carriage rate of $10.6 \%$ with the highest prevalence in the mean age group of 25-29 years (14.9\%) was shown. However, study participants from subgroup 1 had significantly higher GBS colonization rates (15.9\%) compared to pregnant women from subgroup $2(6.0 \%$; $p<0.01)$. According to our logit regression model, pregnant women from Ellembelle district had a 3-fold higher risk having a vaginal GBS colonization than women from other districts. Only three $(1.7 \%)$ out of 177 vaginal specimens were tested positive for C. trachomatis.

Altogether 174 ( $N=6$ missing observations) women showed high levels of HSV IgG. Out of these, twenty (11.5\%) also tested positive for HSV IgM. None of the study participants showed isolated elevated HSV-IgM titers. However, two (1.1\%) out of 180 vaginal swabs were tested positive for HSV DNA, indicating active infection.

\section{High susceptibility for potentially acquiring primary infections}

VZV IgA together with VZV IgG were detected in only $2.4 \%$ of 169 tested women $(N=11$ missing observations), but $54.4 \%$ were positive for only VZV IgG. Since in total $56.8 \%$ were VZV seropositive, a large proportion (43.2\%) was still potentially susceptible for acquiring primary infection. Neither maternal age nor the educational level was significantly different between seropositive and seronegative women. 
Table 2 Prevalence of pathogens, pathogen-specific antigens and antibodies in the study population

\begin{tabular}{|c|c|c|c|c|c|}
\hline \multirow[t]{2}{*}{ Pathogen } & \multirow[t]{2}{*}{ N } & \multicolumn{3}{|c|}{ Serological assays } & \multirow{2}{*}{$\begin{array}{l}\text { Direct } \\
\text { proof }\end{array}$} \\
\hline & & $\lg M$ & $\lg G$ & $\lg A$ & \\
\hline \multicolumn{6}{|c|}{ Current pregnancy-relevant infections } \\
\hline$H B V^{a}(H B s A g$ pos $)$ & 174 & - & - & - & $16.7 \%{ }^{\mathrm{e}}$ \\
\hline Plasmodium spp. ${ }^{b}$ & 180 & - & - & - & $\begin{array}{l}+6 \cdot 1 \% \\
++1.7 \% \\
+++2.8 \%\end{array}$ \\
\hline $\mathrm{GBS}^{\mathrm{C}}$ & 180 & - & - & - & $10 \cdot 6 \%$ \\
\hline HCV & 174 & N/A & $1 \cdot 1 \%$ & $\mathrm{~N} / \mathrm{A}$ & - \\
\hline HIV & 173 & $0.6 \% *^{*}$ & $0.6 \% *$ & $0.6 \% *$ & - \\
\hline C. trachomatis $^{d}$ & 177 & - & - & - & $1.7 \%$ \\
\hline HSV $-1 /-2$ & 174 & $11 \cdot 5 \%$ & $100 \%$ & N/A & $1 \cdot 1 \%^{\mathrm{d}}$ \\
\hline \multicolumn{6}{|c|}{ High susceptibility for potentially acquiring primary infection } \\
\hline VZV & 169 & n.d. & $56 \cdot 8 \%$ & $2.4 \%$ & - \\
\hline T. gondii & 168 & $1.8 \% * *$ & $73.2 \%$ & n.d. & - \\
\hline Parvovirus B19 & 170 & $4.7 \%$ & $80 \cdot 0 \%$ & N/A & - \\
\hline Rubella virus & 172 & $4.7 \%$ & $84 \cdot 3 \%$ & N/A & - \\
\hline \multicolumn{6}{|c|}{ Past pregnancy-relevant infections } \\
\hline CMV & 172 & $0 \%$ & $100 \%$ & N/A & - \\
\hline T. pallidum & 180 & $0 \%^{+}$ & $2 \cdot 8 / 5 \cdot 0 \%^{++}$ & N/A & - \\
\hline \multicolumn{6}{|c|}{ Absence of pregnancy-relevant infections } \\
\hline N. gonorrhoeae ${ }^{c}$ & 180 & - & - & - & 0 \\
\hline Listeria spp. ${ }^{c}$ & 180 & - & - & - & 0 \\
\hline
\end{tabular}

Direct pathogen proof was carried out by antigen test ${ }^{a}$, microscopy and

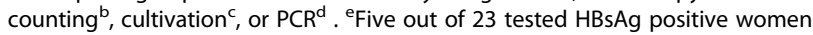
(21.7\%) were also HBeAg positive. -: not applicable. N/A:

not available, n.d.: not done. *the assay used does not discriminate between antibody and antigen, **IgM-positive samples with high IgG avidity,

${ }^{+}$VDRL, ${ }^{++}$FTA-ABS/TPPA

The prevalence of $T$. gondii was determined serologically in 168 blood samples ( $N=12$ missing observations). $73.2 \%$ possessed specific Toxoplasma IgG, out of these, three had elevated levels of Toxoplasma IgM but high Toxoplasma IgG avidity ruling out infections within the last three to four months. Nevertheless, the absence of immunity in $26.8 \%$ of the women poses a risk for primary infection.

Altogether $80 \%$ of 170 women $(N=10$ missing observations) were positive for PB19 IgG and 4.7\% presented with PB19-IgM antibodies. A significant association existed between seropositivity and the number of pregnancies $(p<0.05)$; woman with $>1$ pregnancy had a 3.4-fold higher risk for being seropositive. However, based on our findings, $20 \%$ of the women were seronegative and thus susceptible for acquiring a primary PB19 infection.

Although none of the participants $(N=172, N=8$ missing observations) had received vaccination against rubella virus during childhood, high percentage (79.6\%) of them were tested positive for rubella $\operatorname{IgG}$ without rubella IgM, which confirmed a subsided infection. A further $4.7 \%$ were seropositive for both IgM and IgG antibodies, indicating acute or more recently acquired infections. Absence of IgM and IgG antibodies in 15.7\% identified a group that was susceptible for a primary rubella virus infection.

\section{Prevalence of past infections}

None of 172 women ( $N=8$ missing observations) had HCMV IgM making it likely that acute HCMV infections were not present in the cohort. In contrast, all participants showed high HCMV IgG levels, indicating that they had at least partial immunity to HCMV.

All 180 study participants were screened for syphilis. Nine of them (5\%) showed a positive Treponema pallidum particle agglutination (TPPA) result which indicated acute or past infections. Five (2.8\%) were simultaneously tested positive by the fluorescent treponemal antibody absorption (FTA-ABS) test as well. Since none of them was tested positive by performing the veneral disease research laboratory (VDRL) test, we judged them as subsided syphilis infections. The individuals with an isolated-positive TPPA $(N=4)$ were probably false-positives due to immunological cross-reactions, e.g. with T. pallidum ssp. pertenue causing yaws which is endemic in Ghana.

\section{Absence of infections}

In contrast to GBS, neither L. monocytogenes nor $N$. gonorhoeae could be detected in any of the vaginal swabs. The same was true for Brucella spp. as determined by serology.

\section{Prevalence of coinfections}

Co-infections were only found in pregnant women infected with $\mathrm{HBV}$, the most prevalent current infection in our study sample. Several HBV-positive women were concurrently infected with GBS (1.1\%) or showed serological signs of former contact with $T$. pallidum (0.6\%).

\section{Discussion}

This study provides information on the various infection statuses in the pregnant women in a rural Ghanaian community. Results may be biased by the not included women who do not receive antenatal care, or deliver at home. But according to local authorities this proportion is low on the basis of good medical education, relatively good transport connections of the surrounding communities and the introduction of a general health insurance (covers delivery costs) in 2003. In addition, good medical education may also explain on average 7.8 ANC visits which are far above what is usually seen in low-income settings.

With $10-17 \%$, the most prevalent current pregnancyrelevant infections were hepatitis $B$, malaria, and vaginal GBS colonization. Although hepatitis B played the most important role as pregnancy-relevant infection, we found 
regional differences in HBsAg-carrier rates; a possible explanation for the high prevalence rate in subgroup 1 $(21.8 \%)$ as compared to subgroup $2(11.5 \%)$ may be its more remote location with less access to the public transport system and consequently lower risk of exposure. The overall high HBsAg prevalence of $16.7 \%$ was in agreement with other studies performed in urban areas of Ghana with prevalence rates of $10.6-16 \%[7,8]$. Also in other African countries with similar socio-economic and medical settings, such as Nigeria and Mali, HBsAgcarrier rate has been reported to be considerably high $[9,10]$. Increasing age was not significantly associated with higher HBV prevalence rates in our cohort. This is in agreement with other studies which confirmed the majority of infections to occur in endemic areas by vertical maternofetal transmission [7]. The rate of maternofetal transmission is estimated to be $3-56 \%$, depending on the maternal virus load [8]. More than 20\% of the HBsAgpositive pregnant women in our study were also positive for $\mathrm{HBeAg}$, indicating a high vertical transmission risk. Without vaccination or other medical intervention perinatal HBV infections lead to chronic progression in up to $90 \%$ of the affected newborns who are thus the source for later transmission to their own future offspring [11]. Consequently, efforts towards a gapless antenatal screening and a postnatal vaccination program for neonates of $\mathrm{HBsAg}$ positive mothers need to be intensified in the future.

A substantial decline of placental malaria and maternal anemia with concurrent increase of the birthweight has been ascribed to the introduction of IPTp [12], which is a nationwide medical measure in Ghana since 2004. Although this malaria prophylaxis is well accepted among Ghanaian physicians, its complete implementation remains to be questionable; while $83 \%$ of the surveyed pregnant women of our study indeed received an IPTp, only $34 \%$ of those received the complete treatment with three doses. Thus, a large proportion of $66 \%$ was only preventively treated once or twice, limiting the effectiveness of IPTp. As a consequence, a malaria prevalence of $10.6 \%$ was found in our maternal population which is roughly in accordance with another study from Benin where a prevalence of $15.2 \%$ was found [13]. Thus, the completion of an entire IPTp scheme should be encouraged.

The observed $10.6 \%$ prevalence of vaginal GBS colonization was within the range of $4-25 \%$ shown for low-income countries [14]. Current data indicate a similar importance of GBS in neonatal sepsis with an even higher mortality rate in low-income countries compared to industrialized countries $[15,16]$. Therefore, the role of GBS in neonatal sepsis in rural Ghana needs to be investigated more precisely in the future.

In contrast to the above mentioned infections, much less frequent with prevalence rates of only $0.6-1.7 \%$ were infections with $\mathrm{HCV}, \mathrm{HIV}, \mathrm{C}$. trachomatis, and HSV. The anamnestic finding that $89 \%$ of pregnant woman had been routinely tested on HIV during antenatal care service is clearly an improvement over results from an earlier study in 2007 where only $12 \%$ of expectant mothers were tested nationwide. As a consequence of massive improvement of HIV/AIDS management in the last decades, only one HIV infection was identified in our cohort. The obtained data on HIV nearly equaled the $1.3 \%$ that was estimated in the 2013 sentinel survey in Ghana [17].

Although genital C. trachomatis infections are considered one of the most frequent STIs worldwide [18], its prevalence in Ghana seems to be low. The $1.7 \%$ prevalence rate of vaginal $C$. trachomatis colonization in our study population was similarly low as described for pregnant women in Accra (3.4\%) [19].

The seroprevalence for HSV IgG was $100 \%$ in our study with 20 IgM-positive cases indicating a more recent $\mathrm{HSV}$ infection or reactivation during pregnancy. However, using real-time PCR, genital herpes was only detected in two cases (1.1\%) which was nearly as low as a prevalence of $0.9 \%$ in Zimbabwe [20].

The absence of antibodies in a large proportion of pregnant women make them susceptible to primary infections, as is the case with VZV infection, toxoplasmosis, and infection with PB19 as well as rubella virus in our study cohort.

With $54.4 \%$, the seroprevalence of VZV IgG in our cohort was significantly lower than that in industrialized countries, but in accordance with data from another study which indicated a higher seronegativity rate among immigrants from (sub-) tropical countries [21]. In combination with a non-existing VZV vaccine policy in Ghana, a lower natural virus circulation within the population might be the reason for this seroprevalence rate. Currently, a general VZV screening during pregnancy or selective testing of high-risk groups among pregnant women is not part of the clinical practice in Ghana. Furthermore, hospitals in rural areas do not have the means and resources to treat maternal or neonatal varicella. As a consequence, the incidence of maternal varicella and of congenital varicella syndrome is not known in Ghana.

Our study determined an IgG seroprevalence rate of $73.2 \%$ for $T$. gondii, including $1.1 \%$ of the participants who also tested IgM positive. Since these women presented high IgG avidities, an infection within the last few months was unlikely [22]. However, primary infection acquired during pregnancy could not completely be ruled out, since the screening was conducted in the very last month of pregnancy. Our data on seroprevalence of Toxoplasma IgG are in line with another recent study that showed a prevalence rate of $88.7 \%$ in pregnant women in Accra [23]. In contrast, a significantly lower rate of $20.3 \%$ was determined in Burkina Faso [24]. 
Whether this discrepancy is based on different test systems applied or different environmental burden with parasites remains to be clarified.

We demonstrated prevalence rates for PB19 IgM and $\operatorname{IgG}$ of $4.7 \%$ and $80 \%$, respectively. Although this is in contrast to another study from sub-Saharan Africa with prevalence rates for PB19 IgM of $13.2 \%$ and IgG of $27.5 \%$ [25], absence of antibodies in $20 \%$ in our cohort makes them susceptible to primary infection. Similarly, we documented absence of antibodies against rubella virus in $15.7 \%$ of women in our cohort indicated that a significant proportion was susceptible to primary infection during pregnancy. This rate was twice as high as the one reported for Tanzania and argues in favor of a future vaccination program in low-endemic countries of sub-Saharan Africa [26].

The seroprevalence of HCMV IgG in our cohort was $100 \%$, indicating past infection and making it unlikely that HCMV poses a major threat for prenatal transmission to the child in rural Ghana. Our results are significantly higher than the rate of $72.2 \%$ that was recently determined in Sudan [27]. Although a perinatal or postnatal HCMV transmission from IgG-seropositive mothers to their children is possible $[28,29]$, full-term infants are protected by maternal IgG in most cases and rarely develop symptoms.

Whereas no infection with $N$. gonorrhoeae could be identified, $5 \%$ had TPPA-reactive antibodies. Based on the results of the FTA-ABS and VDRL tests, we could not find active syphilis among our pregnant study participants. The TPPA results of our rural cohort matched with the outcome of another study performed in an urban Ghanaian community with a prevalence rate of 7.1\% [19]. Finally, the absence of infections with $L$. monocytogenes and Brucella spp. might be based on the exclusive consumption of canned milk as only source of dairy products in our cohort.

\section{Conclusions}

Mother and child morbidity and mortality rates in lowincome countries are still among the highest in the world. Although non-communicable diseases are emerging in sub-Saharan Africa in the context of mother-child-health issues, infectious diseases play a major role. In Ghana, as in many other countries of sub-Saharan Africa, several diseases compete for the limited public health resources. Our pilot study indicates the existence of pregnancyrelevant infections in a rural population at different prevalence rates and indicates urgent need for action in dealing at least with those of high prevalence, such as hepatitis B, malaria and infections caused by group B streptococci. In addition, the resulting prevalence rates of various other infections may offer guidance for health officials to prioritize possible future intervention schemes.

\section{Additional file}

Additional file 1: Structured questionnaire. Participants of the study were interviewed to collect general, demographic, and obstetric data using the structured questionnaire. (PDF $417 \mathrm{~kb}$ )

\begin{abstract}
Abbreviations
ALT: Alanine aminotransferase; ANC: Antenatal clinic; FTA-ABS: Fluorescent treponemal antibody absorption; GBS: Group B streptococci; HBeAg: Hepatitis B excretory antigen; HBsAg: Hepatitis B surface antigen; HBV: Hepatitis B virus; HCMV: Human cytomegalovirus; HCV: Hepatitis C virus; HIV: Human immunodeficiency virus; HSV: Herpes simplex virus; IPTp: Intermittent preventive treatment during pregnancy; MALDI-TOF: Matrix-assisted laser desorption/ ionization time-of-flight; MS: Mass-spectrometry; PB19: Parvovirus B19;

PCR: Polymerase chain reaction; spp.: Species; TPPA: Treponema pallidum particle assay; VDRL: Veneral disease research laboratory; VZV: Varicella zoster virus
\end{abstract}

\section{Acknowledgements}

We are grateful to the patients who contributed samples and were willing to give an interview. We thank the laboratory teams in Eikwe and Göttingen for their excellent technical assistance.

\section{Funding}

No funding was received for the study.

Availablity of data and materials

The anonymized data supporting our results can be obtained on request to the corresponding author Dr. Groß.

\section{Authors' contributions}

UG conceived and designed the study. FV, PC, OB, AU, OZ, RL collected data. $\mathrm{FV}, \mathrm{OB}, \mathrm{OZ}, \mathrm{RL}, \mathrm{UG}$ analyzed and interpreted data. FV did the statistical analysis. FV, RL, UG drafted the manuscript. PC, OB, OZ critically revised the manuscript for important intellectual content. UG supervised the study. All authors have read and approved the final version of this manuscript.

\section{Competing interests}

The authors declare that they have no competing interests.

\section{Consent for publication}

Not applicable.

\section{Ethics approval and consent to participate}

This study was approved by the ethical committee of the University Medical Centre Göttingen, Germany, and the participating St. Martin de Porres

Hospital, Eikwe, Ghana (No. 14/10/11). Education and informed consent were translated by study assistants into the two most common languages, Nzema and Akan. Consents were recorded in written form with signature or personal fingerprint in case of illiterate study participants. This consent procedure was confirmed by the ethical committee.

\section{Publisher's Note}

Springer Nature remains neutral with regard to jurisdictional claims in published maps and institutional affiliations.

\section{Author details}

${ }^{1}$ Institute for Medical Microbiology, University Medical Center Göttingen, Kreuzbergring 57, D-37075 Göttingen, Germany. ${ }^{2}$ St. Martin de Porres Hospital, Eikwe, W/R, Ghana. ${ }^{3}$ Göttingen International Health Network, Göttingen, Germany.

Received: 1 February 2017 Accepted: 26 May 2017

Published online: 06 June 2017

\section{References}

1. Alkema L, Chou D, Hogan D, Zhang S, Moller AB, Gemmill A, et al. Global, regional, and national levels and trends in maternal mortality between 1990 and 2015, with scenario-based projections to 2030: a systematic analysis by the UN maternal mortality estimation inter-agency group. Lancet. 2016;387:462-74. 
2. WHO. Trends in maternal mortality: 1990 to 2015. http://apps.who.int/ iris/bitstream/10665/194254/1/9789241565141_eng.pdf? (accessed January $21^{\text {st }}$ 2017).

3. Say L, Chou D, Gemmill A, Tuncalp Ö, Moller AB, Daniels J, et al. Global causes of maternal death: a WHO systematic analysis. Lancet Global Health. 2014;2:e323-33.

4. Kinney MV, Kerber KJ, Black RE, Cohen B, Nkrumah F, Coovadia H, et al. SubSaharan Africa's mothers. Newborns, and childrern: where and why do they die? PLoS Med. 2010;7:e1000294.

5. Nkhoma ET, Bowman NM, Kalilani-Phiri L, Mwapasa V, Rogerson SJ, Meshnick SR. The effect of HIV infection on the risk, frequency, and intensity of Plasmodium falciparum parasitemia in primigravid and multigravid women in Malawi. Am J Trop Med Hyg. 2012;87:1022-7.

6. Kish L. Sampling organizations and groups of unequal sizes. Am Sociol Rev. 1965:30:564-72.

7. Cho Y, Bonsu G, Akoto-Ampaw A, Nkrumah-Mills G, Nimo JJ, Park JK, et al. The prevalence and risk factors for hepatitis B surface ag positivity in pregnant women in eastern region of Ghana. Gut Liver. 2012;6:235-40.

8. Candotti D, Danso K, Allain JP. Maternofetal transmission of hepatitis B virus genotype E in Ghana, West Africa. J Gen Virol. 2007;88:2686-95.

9. Olokoba AB, Salawu FK, Danburam A, Olokaba LB, Midala JK, Badung LH, et al. Hepatitis $B$ virus infection amongst pregnant women in north-eastern Nigeria- a call for action. Niger J Clin Pract. 2011;14:10-3.

10. MacLean B, Hess RF, Bonvillain E, Kamate J, Dao D, Cosimano A, et al. Seroprevalence of hepatitis B surface antigen among pregnant women attending the Hospital for Women \& children in Koutiala, Mali. S Afr Med J. 2012;102:47-9.

11. Kramvis A. The clinical implications of hepatitis B virus genotypes and HBeAg in pediatrics. Rev Med Virol. 2016;26:285-303.

12. Hommerich L, von Oertzen C, Bedu-Addo G, Holmberg V, Acquah PA, Eggelte TA, et al. Decline of placental malaria in southern Ghana after the implementation of intermittent preventive treatment in pregnancy. Malar J. 2007;6:144.

13. Ouédraogo S, Koura GK, Accrombessi MM, Bodeau-Livinec F, Massougbodji A, Cot M. Maternal anemia at first antenatal visit: prevalence and risk factors in a malaria-endemic area in Benin. Am J Trop Med Hyg. 2012;87:418-24.

14. Marai W. Lower genital tract infections among pregnant women: a review. East Afr Med J. 2001;78:581-5.

15. Gray KJ, Bennett SL, French N, Phiri AJ, Graham SM. Invasive group B streptococcal infection in infants, Malawi. Emerg Infect Dis. 2007;13:223-9.

16. Watson RS, Carcillo JA, Linde-Zwirble WT, Clermont G, Lidicker J, Angus DC. The epidemiology of severe sepsis in children in the United States. Am J Respir Crit Care Med. 2003;167:695-701.

17. Ghana AIDS Commission. Summary of the 2013 HIV Sentinel Survey Report. http://ghanaids.gov.gh/gac1/aids_info.php (accessed January $21^{\text {st }}$ 2017).

18. Markle W, Conti T, Kad M. Sexually transmitted diseases. Prim Care. 2013:40:557-87.

19. Apea-Kubi KA, Yamaguchi S, Sakyi B, Kishimoto T, Ofori-Adjei D, Hagiwara T. Neisseria gonorrhoea, Chlamydia trachomatis, and Treponema pallidum infection in antenatal and gynecological patients at Korle-Bu teaching hospital, Ghana. Jpn J Infect Dis. 2004;57:253-6.

20. Latif AS, Mason PR, Marova E, Gwanzura L, Chingono A, Mbengeranwa OL. Risk factors for gonococcal and chlamydial cervical infection in pregnant and non-pregnant woman in Zimbabwe. Cent Afr J Med. 1999;45:252-8.

21. van Rijckevorsel GG, Damen M, Sonder GJ, van der Loeff MF, van den Hoek A. Seroprevalence of varicella-zoster virus and predictors for seronegativity in the Amsterdam adult population. BMC Infect Dis. 2012;12:140.

22. Montoya JG, Liesenfeld O, Kinney S, Press C, Remington JS. VIDAS test for avidity of Toxoplasma-specific immunoglobulin $\mathrm{G}$ for confirmatory testing of pregnant women. J Clin Microbiol. 2002;40:2504-8.

23. Ayi I, Edu SA, Apea-Kubi KA, Boamah D, Bosompem KM, Edoh D. Seroepidemiology of toxoplasmosis amongst pregnant women in the greater Accra region of Ghana. Ghana Med J. 2009:43:107-14.

24. Linguissi LS, Nagalo BM, Bisseye C, Kagoné TS, Sanou M, Tao I, et al. Seroprevalence of toxoplasmosis and rubella in pregnant women attending antenatal private clinic at Ouagadougou, Burkina Faso. Asian Pac J Trop Med. 2012;5:810-3.

25. Emiasegen SE, Nimzing L, Adoga MP, Ohagenyi AY, Lekan R. Parvovirus B19 antibodies and correlates of infection in pregnant women attending an antenatal clinic in central Nigeria. Mem Inst Oswaldo Cruz. 2011;106:227-31.
26. Mwambe B, Mirambo MM, Mshana SE, Massinde AN, Kidenya BB, Morona D, et al. Sero-positivity rate of rubella and associated factors among pregnant women attending antenatal care in Mwanza, Tanzania. BMC Pregnancy Childbirth. 2014:14:95. doi:10.1186/1471-2393-14-95.

27. Hamdan HZ, Abdelbagi IE, Nasser NM, Adam I. Seroprevalence of cytomegalovirus and rubella among pregnant women in western Sudan. Virol J. 2011;8:217.

28. Vochem M, Hamprecht $K$, Jahn G, Speer CP. Transmission of cytomegalovirus to preterm infants through breast milk. Pediatr Infect Dis J. 1998;17:53-8.

29. Johnson J, Anderson B, Pass RF. Prevention of maternal and congenital cytomegalovirus infection. Clin Obstet Gynecol. 2012;55:521-30.

\section{Submit your next manuscript to BioMed Central and we will help you at every step:}

- We accept pre-submission inquiries

- Our selector tool helps you to find the most relevant journal

- We provide round the clock customer support

- Convenient online submission

- Thorough peer review

- Inclusion in PubMed and all major indexing services

- Maximum visibility for your research

Submit your manuscript at www.biomedcentral.com/submit
Biomed Central 